intra renal surgery (ECIRS). Multilingual DVD presentation. Karl Storz Endoskope. Tuttlingen. Endopress 2007.

8. Park S: Editorial Comment in: Steerable antegrade stenting: A new trick of the trade. Int Braz J Urol. 2007; 33: 393-4.
9. Liatsikos EN, Voudoukis TH: Editorial Comment in: Steerable antegrade stenting: A new trick of the trade. Int Braz J Urol. 2007; 33: 394.

10. Macri A, Magno C, Certo A: Combined antegrade and retrograde ureteral stenting: The rendezvous technique. Clin Radiol. 2005; 60: 457-60.

Dr. José Gabriel Valdivia Uría

Department of Urology

Universitary Hospital Lozano Blesa

Saragossa, Spain

E-mail: jvaldivia@salud.aragon.es

\title{
Re: Lack of Association between Matrix Metalloproteinase-1 (MMP-1) Promoter Polymorphism and Risk of Renal Cell Carcinoma
}

Michelly F. Piccoli, Marcia Figueira, Cassio Andreoni, Julio T. Marumo, Nestor Schor, Maria H. Bellini

Section of Nephrology (MFP, MF, NS, MHB) and Section of Urology (CA), Federal University of Sao Paulo, UNIFESP, and Institute of Energetic and Nuclear Research (JTM, MHB), Sao Paulo, SP, Brazil

Int Braz J Urol, 33: 622-629, 2007

To the Editor:

Matrix Metalloproteinases (MMPs) are a family of extracellular matrix degradative enzymes physiologically involved in tissue development and remodeling. Now they are being widely studied for their potential role in the progression and metastasis of many tumors (1).
Indeed degradation of extracellular matrix is one of the crucial and early steps in many carcinomas. The role of the huge family of these enzymes and their inhibitors in cancer cells invasion, metastasis (2), proliferation and angiogenesis (3) is probably much more complex than it seems and still needs to be clarified. 
On these basis, many authors paid attention to the overexpression of MMPs enzymes in renal cell carcinoma (RCC). Overexpression of MMP2 and MMP9 has been described in association with poor prognosis of patients with RCC (4-6). Overexpression of MMP1, MMP3, MMP7, MMP11, MMP12 and MMP14 has been described in tissue of $\operatorname{RCC}(7,8)$. More recently, a strong relation between MMP10 expression and stage and grade of RCC has been demonstrated (9).

These growing evidences of MMPs role in $\mathrm{RCC}$ pathogenesis is the strong rationale to plan genetic investigation to assess not only the phenotype but the genotype modification that stand behind RCC development and progression.

The genetic population based studies are mainly aimed at identifying groups at a higher risk of developing a cancer or at a higher risk of having a cancer with a worse prognosis. The case control population based researches are often biased by not controllable factors especially when the sample size is limited. Moreover, the results of genetic studies are complicated by the wide heterogeneity between different ethnic groups. To draw any conclusion from genetic statistics we need wide sample sizes, from different regions to compare the results of different ethnic groups.

The efforts and the costs of such studies are worthy. Indeed the future possibility of identifying a high-risk group for RCC by a simple test for genetic polymorphism will lead to an early diagnosis of cancer in these patients. The people bearing the highrisk alleles will take advantage of a strict clinical surveillance for example with periodic ultrasound scan.

Even if the results of the authors do not allow identifying an increased risk of RCC for the MMP1 promoter polymorphism in Brazil, they are still important. If further data support these results, the geneticists will have to search for more loci in order to identify one or more gene polymorphisms responsible for increased risk of RCC in Brazil. If further data do not support the result of the aforementioned study, the geneticists will have to plan a wider population based study to answer to the question about the MMP1 promoter polymorphism and the risk of RCC in Brazil.

\section{REFERENCES}

1. Arribas J: Matrix metalloproteases and tumor invasion. N Engl J Med. 2005; 352: 2020-1.

2. Egeblad M, Werb Z: New functions for the matrix metalloproteinases in cancer progression. Nat Rev Cancer. 2002; 2: 161-174.

3. Deryugina EI, Quigley JP: Matrix metalloproteinases and tumor metastasis. Cancer Metastasis Rev. 2006; 25: $9-34$.

4. Lein M, Jung K, Laube C, Winkelmann B, Stephan C, Hauptmann S, et al.: Matrix metalloproteinases and their inhibitors in plasma and tumor tissueof patients with renal cell carcinoma. Int J Cancer. 2000; 85: 801-4.

5. Slaton JW, Inoue $\mathrm{K}$, Perrotte $\mathrm{P}, \mathrm{El}-\mathrm{Naggar} \mathrm{AK}$, Swanson DA, Fidler IJ, et al.: Expression levels of genes that regulate metastasis and angiogenesis correlate with advanced pathological stage of renal cell carcinoma. Am J Pathol. 2001; 158: 735-43.

6. Cho NH, Shim HS, Rha SY, Kang SH, Hong SH, Choi YD, et al.: Increased expression of metalloproteinase 9 correlates with poor prognostic variables in renal cell carcinoma. Eur Urol. 2003; 44: 560-6.

7. Hagemann T, Gunawan b, Schulz M, Füzesi L, Binder $\mathrm{C}$ : mRNA expression of matrix metalloproteinases and their inhibitors differs in subtypes of renal celle carcinomas. Eur J Cancer. 2001; 37: 1839-46.

8. Sumi T, Nakatani T, Yoshida H, Hyun Y, Yasui T, Matsumoto $\mathrm{Y}$, et al.: Expression of matrix metalloproteinase-7 and 2 in human renal cell carcinoma. Oncol Rep. 2003; 10: 567-70.

9. Miyata Y, Iwata T, Maruta S, Kanda S, Nishikido M, Koga S, et al.: Expression of matrix metalloproteinase10 in renal cell carcinoma and its prognostic role. Eur Urol. 2007; 52: 791-7.

Dr. Andrea Zitella Dr. Paolo Gontero Ricercatore in Urologia Università di Torino Ospedale Molinette, Torino, Italy E-mail:paolo.gontero@unito.it 